\title{
Ultrasonography-guided reduction of pediatric radial neck fractures
}

\author{
Jung Eun Lee, Jung Bong Kim and Eun Seok Choi ${ }^{*}$
}

\begin{abstract}
Background: Treatment of displaced and angulated radial neck fractures in children is controversial and challenging. Numerous studies have been conducted regarding treatment algorithms and surgical techniques that use fluoroscopy. However, ultrasonography (US)-guided reduction of pediatric radial neck fractures has not been reported yet. We aimed to determine the safety and efficacy of US-guided reduction and fixation of radial neck fractures in children.

Methods: Among 28 cases of radial neck fracture from 2014 to 2016, 12 were classified as type III or IV according to the Judet classification. All 12 patients underwent US-guided reduction and percutaneous fixation with Kirschner wire and follow-up for more than 6 months. US was used primarily to monitor the angulation and reduction of the radial neck. Fluoroscopy was applied to confirm the fixation with Kirschner wire. Dose area product (DAP; $\mathrm{mGy} / \mathrm{cm}^{2}$ ) was measured to assess per-procedure radiation dose. Radiological and clinical results were evaluated at 6 months after the surgery by using the Metaizeau criteria.

Results: Of the patients, 4 were boys and 8 were girls, with a mean age of 7.7 years (range, 5-11 years). Judet type III fractures accounted for $83 \%$ of all injuries. The mean preoperative radial angulation was $62.5^{\circ}$ (range: $46^{\circ}-76^{\circ}$ ). The mean postoperative radial angulation was $5.6^{\circ}$ (range: $2^{\circ}-9^{\circ}$ ). The mean fluoroscopy time was $31 \mathrm{~s}$ (range: $10-73 \mathrm{~s}$ ), and the mean DAP was $10.7 \mathrm{mGy} / \mathrm{cm}^{2}$ (range: $7.2-18.7 \mathrm{mGy} / \mathrm{cm}^{2}$ ). The mean follow-up period was 18.3 months (range, 824 months). According to the Metaizeau criteria, 10 cases were excellent and 2 cases were good the last follow-up.
\end{abstract}

Conclusions: US-guided reduction and percutaneous fixation is safe and reliable option to treat displaced radial neck fractures in children.

Keywords: Radial neck fractures, Children, Ultrasonography, Percutaneous pinning

\section{Background}

Radial neck fractures account for approximately $1 \%$ of all fractures in children. However, the treatment of displaced and angulated fractures is controversial and challenging [1]. In terms of surgical treatment, several techniques have been documented. Closed surgeries using various reduction techniques, including percutaneous pin or intramedullary elastic nails, have been proposed [1-8]. However, concerns about inadequate reduction, epiphyseal damage, and posterior interosseous nerve injury have emerged $[4,9]$. The radial head start to ossify from around age 5 years; if the radial head is mostly cartilaginous, it may be difficult to visualize on

\footnotetext{
* Correspondence: stoneos98@gmail.com

Department of Orthopaedic Surgery, Gachon University Gil Hospital,

Namdong-daero 774 beon-gil, Namdong-gu, Incheon 21565, South Korea
}

radiography. Hence, identification and precise reduction of radial neck fractures by using an intraoperative image intensifier can be limited, and exposure to ionizing radiation can be increased [10].

For the diagnosis of pediatric fractures, the efficacy and reliability of ultrasonography (US) has been demonstrated by several researches [11-14]. However, only few studies have reported the use of US in orthopedic surgeries [15]. We have treated severely displaced radial neck fractures with the percutaneous leverage reduction technique using intraoperative US guidance. To our knowledge, intraoperative use of US for the reduction of radial neck fracture has not been reported yet. The aim of our study was to determine the safety and efficacy of US-guided reduction and fixation of radial neck fractures in children. 


\section{Methods}

We retrospectively reviewed the medical records of 28 children with radial neck fractures from 2014 to 2016. Patients with severely angulated radial neck fracture, classified as type III or IV according to the Judet classification, underwent US-guided reduction and fixation with Kirschner wire (K-wire) [5]. The inclusion criteria were as follows: (1) 3-16 years of age, (2) sufficient radiological and medical records, and (3) follow-up for $>6$ months after surgery. Two patients with multiple fractures and one patient with previous history of supracondylar fracture were excluded. Twelve patients satisfied the inclusion criteria. Medical records, including demographic data, injury characteristics(mechanism of injury, Judet's classification and direction of displacement), radiation exposures and treatment outcomes were reviewed. Their mean age at surgery was 7.7 years (range, 5-11 years). Of the patients, 4 were boys and 8 were girls. The mean follow-up period was 18.3 months (range, 8-24 months). Slipping down was the most common cause of injury (Table 1). Prior institutional review board (IRB) approval was obtained for this study.

\section{Surgical techniques}

All surgeries were performed at a single institution by one surgeon (ESC). Under general anesthesia, the fractured elbow is extended and the forearm is supinated. A mobile image intensifier (Fluoroscan Insight, Hologic Inc., Bedford, MA/USA) and US (z.one SmartCart, Zonare Medical Systems, Mountain View, CA/USA) were set to be used simultaneously. US was used primarily to monitor the angulation and reduction of the radial neck (Fig. 1). The transducer was placed with its longitudinal axis on the radial shaft. A 2.0-mm Steinmann pin was inserted from the distal and lateral aspects to the fracture site, under US guidance (Fig. 2). US allowed for continuous monitoring of the reduction with a
Steinmann pin. After satisfactory reduction was confirmed on US, the radial head is buttressed by the thumb of the operator. We used fluoroscopy for in situ fixation with a second K-wire. The trajectory of the second Kwire was more proximal to the radius than that of the first one and overlapped with the US probe. Moreover, fluoroscopy is essential to check the penetration into the far cortex (Fig. 3). Postoperative care included immobilization using a long arm cast for 3 weeks. The K-wire was removed along with the cast at 3 weeks after surgery in the outpatient clinic. Then, a hinged brace was applied for 3 weeks.

\section{Postoperative evaluation}

Dose area product (DAP; $\mathrm{mGy} / \mathrm{cm}^{2}$ ) was measured through the ionization chamber in the mobile image intensifier and used to assess per-procedure radiation dose. Clinical results were evaluated at 6 months after the surgery by using the Metaizeau criteria as follows: excellent, if the fracture healed at the appropriate anatomical position and full range of motion (ROM); good, if the radial neck flexion angle was $<20^{\circ}$ and the loss of ROM (including flexion, extension, pronation, or supination) was $<20^{\circ}$ without pain; fair, if the radiological angle was $20-40^{\circ}$ and the loss of ROM was $<40^{\circ}$ with mild instability or pain; poor, if the radiological angle was $>40^{\circ}$ and the loss of $\mathrm{ROM}$ was $>40^{\circ}$ with residual pain or instability. $[5,16]$ Statistical analyses were performed using $\mathrm{SPSS}^{\circledR}$ software (Version 18.0; SPSS Inc., Chicago, IL, USA).

\section{Results}

Judet type 3 fractures account for $83 \%$ of all injuries. The mean preoperative radial angulation was $62.5^{\circ}$ (range: $46^{\circ}-76^{\circ}$ ). The mean postoperative radial angulation was $5.6^{\circ}$ (range: $2^{\circ}-9^{\circ}$ ). The mean fluoroscopy time

Table 1 Clinical characteristics of patients

\begin{tabular}{|c|c|c|c|c|c|c|c|}
\hline Number & Age & Side & Mechanism of Injury & Judet Classification & Direction of Displacement & $\mathrm{DAP}\left(\mathrm{mG} / \mathrm{cm}^{2}\right)$ & Clinical Result \\
\hline 1 & 7 & $\mathrm{Rt}$ & Fall from the height & III & Lateral & 15.2 & Excellent \\
\hline 2 & 7 & Rt & Slip down & III & Lateral & 12.9 & Excellent \\
\hline 3 & 5 & $L t$ & Slip down & III & Lateral & 11.6 & Excellent \\
\hline 4 & 5 & Rt & Trampoline Injury & III & Lateral & 10.5 & Excellent \\
\hline 5 & 6 & Rt & Slip down & III & Lateral & 8.2 & Excellent \\
\hline 6 & 11 & $\mathrm{Lt}$ & Slip down & $\mathrm{IVa}$ & Lateral & 18.7 & Good \\
\hline 7 & 10 & $\mathrm{Lt}$ & Sports Injury & III & Lateral & 7.2 & Good \\
\hline 8 & 5 & $L t$ & Slip down & III & Posterior & 8.4 & Excellent \\
\hline 9 & 11 & Rt & Slip down & $\mathrm{IVa}$ & Posterolateral & 12.7 & Excellent \\
\hline 10 & 8 & Rt & Fall from the height & III & Lateral & 7.2 & Excellent \\
\hline 11 & 8 & $\mathrm{Lt}$ & Fall from the height & III & Lateral & 7.4 & Excellent \\
\hline 12 & 9 & Rt & Slip down & III & Lateral & 8.2 & Excellent \\
\hline
\end{tabular}




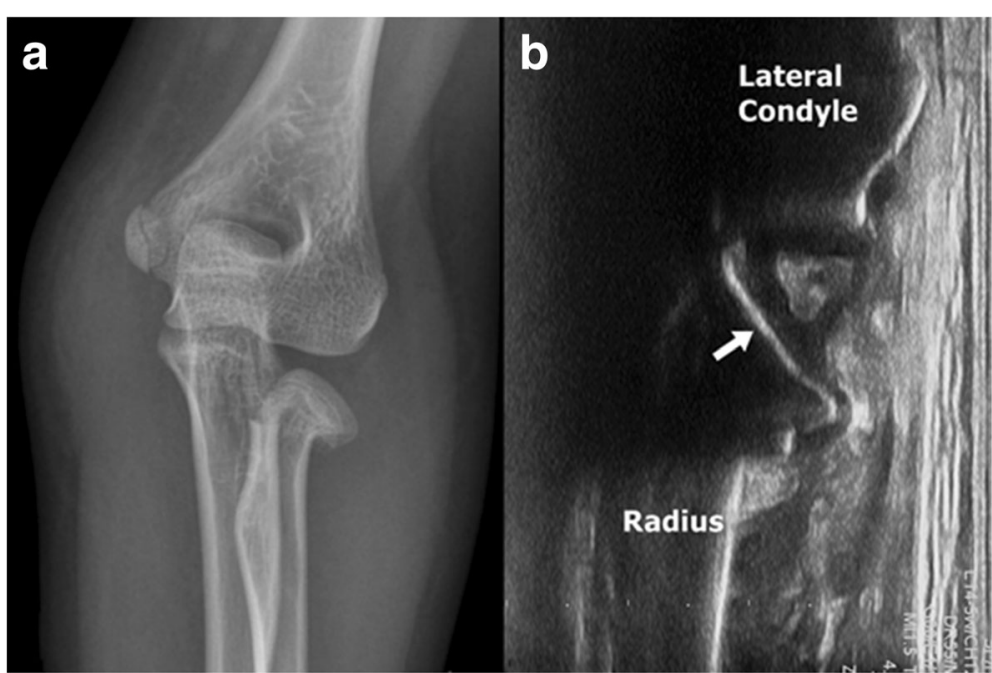

Fig. 1 Radiographic and ultrasonographic views of the radial neck fracture. a Radial neck fracture Judet grade 3. b Intraoperative ultrasonographic view of the fracture. The reverberating echo of the angulated radial head (arrow) is clearly visible

was $31 \mathrm{~s}$ (range: 10-73 s), and the mean DAP was $10.7 \mathrm{mGy} / \mathrm{cm}^{2}$ (range: $7.2-18.7 \mathrm{mGy} / \mathrm{cm}^{2}$ ).

No nerve injury occurred during the follow-up. Superficial pin site infection occurred in 1 patient but was controlled with oral antibiotics without complications. Long-term complications, including avascular necrosis or synostosis, were not found. According to the Metaizeau reduction classification, 10 cases were excellent and 2 cases were good. One case with good result showed slight angulation $\left(15^{\circ}\right)$ of the radial neck with full ROM at last follow-up (12 months). The other case with good result had limited elbow flexion $\left(10^{\circ}\right)$ without discomfort at last follow-up (12 months).

\section{Discussion}

One of the fundamental ALARA ('as low as reasonably achievable') principles is to minimize or avoid radiation whenever possible [17]. Use of US rather than radiography is a representative recommendation based on the ALARA principle, and its advantages for the diagnosis of pediatric fractures has been demonstrated [11-13, 18, 19]. Several reports demonstrated the efficacy and safety of US-guided reduction of fractures at the emergency department. However, only few studies have been conducted regarding the intraoperative use of US for fracture reduction and fixation. As a first report of a USguided reduction of radial neck fractures, our results demonstrated that US-guided reduction and fixation

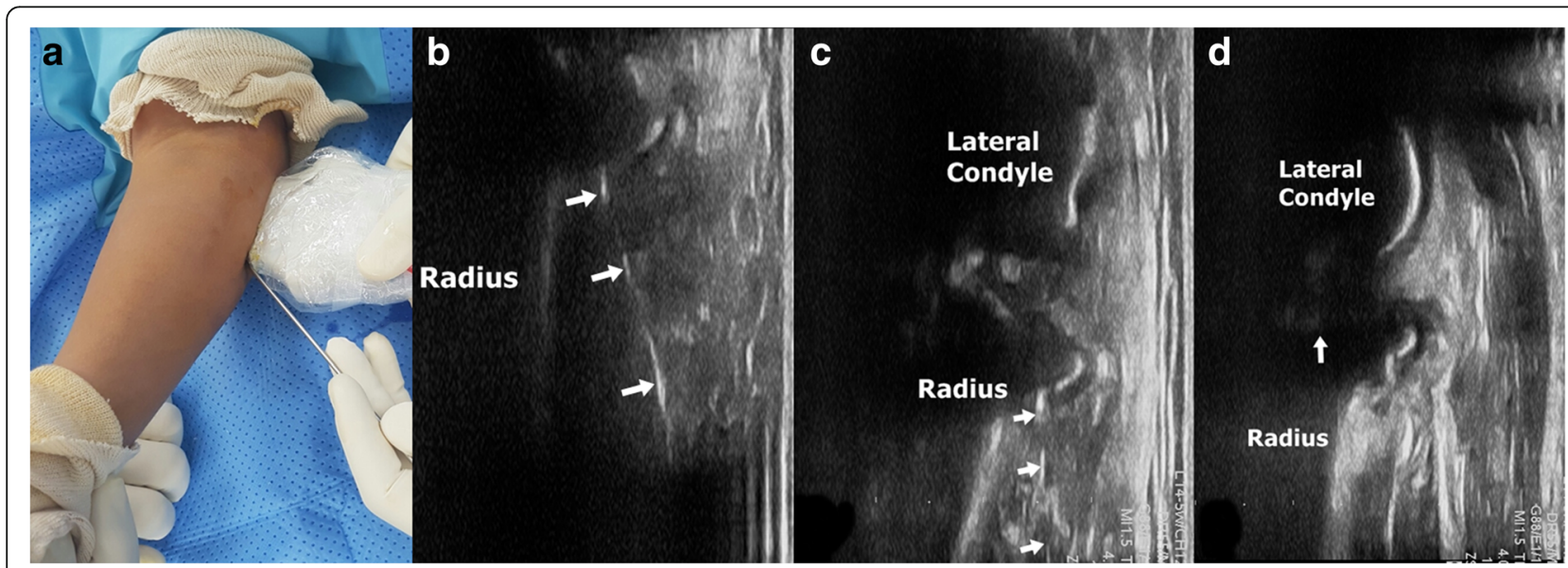

Fig. 2 US-guided reduction of radial neck fracture. a intraoperative setting of US-guided reduction. b Steinman pin(arrows) was introduced from the distal to the radial neck. c Reduction of radial neck under the continuous guide of US. $\mathbf{d}$ The reverberating echo of angulated radial head(Fig. 1 b) is disappeared(arrow) after complete reduction 


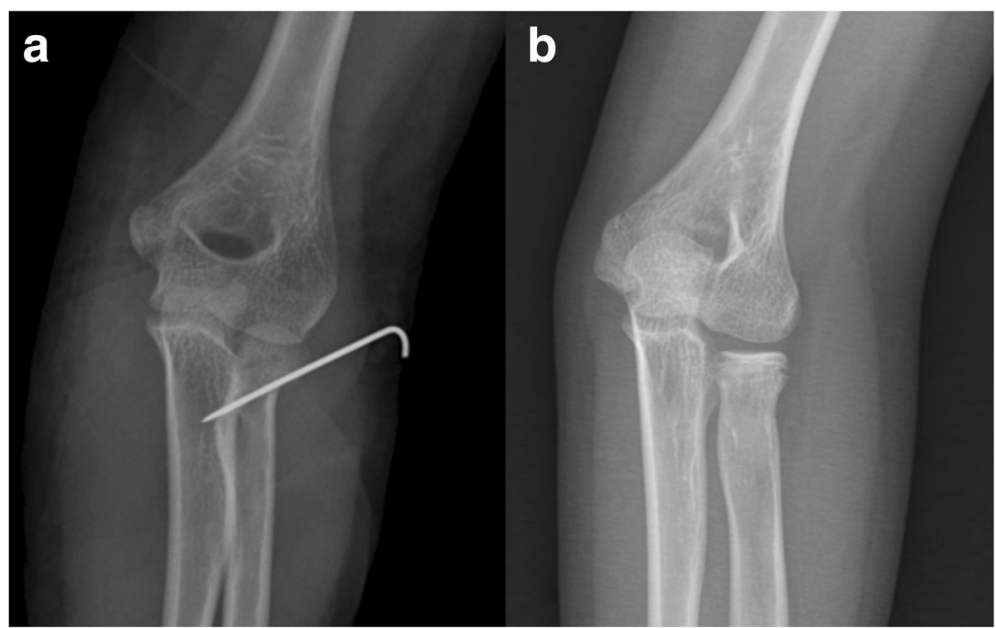

Fig. 3 a Percutaneous pinning under fluoroscopy guide. $\mathbf{b}$ Final outcome at 6 months of follow-up

could be a useful treatment option for pediatric radial neck fractures.

A recent quantification study of radiation exposures in 248 children reported that the mean DAP exposure of supracondylar fractures and flexible nailing of the forearm were 22.3 and $26.7 \mathrm{mGy} / \mathrm{cm}^{2}$, respectively [20]. One study documented that the mean DAP of elbow fracture treatments performed by experienced surgeons was $87.41 \mathrm{mGy} / \mathrm{cm}^{2}$ [21]. Poor visualization of the radial head and neck, especially in young children, can increase radiation use. In contrast to those studies, we can reduce the radiation exposure (mean DAP: $10.7 \mathrm{mGy} / \mathrm{cm}^{2}$ ) by using US and fluoroscopy in combination.

US has several advantages over radiography in the diagnosis and treatment of pediatric fractures. Fluoroscopy has limitations in identifying pediatric bone with incomplete ossification, especially the radial head of young children [10]. Fractures could be sonographically identified along with subperiosteal hematomas, deformities, cortical disruption, and reverberating echoes [18]. Several researches demonstrated high sensitivity $(86.6 \%-97 \%)$ and specificity $(86.6 \%-100 \%)$ for fractures of the forearm bone and humerus [12, 13, 19]. In radial neck fractures, the reverberating echo of the radial head is clearly visible and allows for easy assessment of the angulation (Fig. 1). The authors can identify the Steinman pin for reduction and constantly monitor the reduction of the fracture in multiple planes with US (Fig. 2). US can be used to detect associated soft tissue injuries such as tendon injury, hematoma, and nerve injury. However, the use of US for the treatment of fractures has limitations arising from its inability to penetrate the bone. Fluoroscopy is required for bicortical fixation because USG can identify only the near cortex of the bone.

\section{Limitations}

This study has some limitations. The small number of patients included in the study may not be enough to prove the efficacy of our novel technique. Another limitation comes from the design of the study. Although US-guided treatment appears to reduce radiation exposure, further prospective and randomized research is required.

\section{Conclusion}

The present study demonstrated that US-guided reduction can be considered a safe and reliable treatment option for displaced radial neck fractures in children.

\section{Abbreviations \\ DAP: Dose area product; US: Ultrasonography}

\section{Acknowledgements}

Not applicable.

\section{Funding}

This research did not receive any specific grant from funding agencies in the public, commercial, or not-for-profit sectors.

\section{Availability of data and materials}

The datasets used and/or analyzed during the present study are available from the corresponding author on reasonable request.

\section{Authors' contributions}

ESC and JEL designed the study; ESC and JBK collected and analyzed the data; and ESC and JEL wrote the manuscript. All authors have read and approved the final manuscript.

\section{Ethics approval and consent to participate}

This study was approved by the institutional review board of Gachon University Gil Medical Center (ethics approval code: GCIRB No. 2017-288). The need for consent was waived by the institutional review board of Gachon University Gil Medical Center (ethics approval code: GCIRB No. 2017288). Radiologic images are entirely unidentifiable and there are no details on individuals reported within the manuscript. 


\section{Consent for publication}

Not applicable.

\section{Competing interests}

The authors declare that they have no competing interests.

\section{Publisher's Note}

Springer Nature remains neutral with regard to jurisdictional claims in published maps and institutional affiliations.

Received: 8 September 2017 Accepted: 4 December 2017

Published online: 08 December 2017

\section{References}

1. Jiang $H$, Wu $Y$, Dang $Y$, Qiu $Y$. Closed reduction using the percutaneous leverage technique and internal fixation with K-wires to treat angulated radial neck fractures in children-case report. Medicine. 2017:96(1):e5806.

2. Cha SM, Shin HD, Kim KC, Han SC. Percutaneous reduction and leverage fixation using K-wires in paediatric angulated radial neck fractures. Int Orthop. 2012;36(4):803-9.

3. Choi WS, Han KJ, Lee DH, Lee GE, Kweon HJ, Cho JH. Stepwise percutaneous leverage technique to avoid posterior interosseous nerve injury in pediatric radial neck fracture. J Orthop Trauma. 2017;31(5):e151-7.

4. Eberl R, Singer G, Fruhmann J, Saxena A, Hoellwarth ME. Intramedullary nailing for the treatment of dislocated pediatric radial neck fractures. Eur J Pediatr Surg. 2010:20(4):250-2.

5. Metaizeau JP, Lascombes P, Lemelle JL, Finlayson D, Prevot J. Reduction and fixation of displaced radial neck fractures by closed intramedullary pinning. J Pediatr Orthop. 1993;13(3):355-60.

6. Song KS, Kim BS, Lee SW. Percutaneous leverage reduction for severely displaced radial neck fractures in children. J Pediatr Orthop. 2015;35(4): e26-30.

7. Tarallo L, Mugnai R, Fiacchi F, Capra F, Catani F. Management of displaced radial neck fractures in children: percutaneous pinning vs. elastic stable intramedullary nailing. J Orthop Traumatol. 2013;14(4):291-7.

8. Serbest S, Gurger M, Tosun HB, Karakurt L. Closed reduction and intramedullary pinning in the treatment of adult radial neck fractures: a case report. The Pan African medical journal. 2015;20:434.

9. Terra BB, Sassine TJ, Lima GF, Rodrigues LM, Padua DV, Nadai A. Radial head fracture associated with posterior interosseous nerve injury. Rev Bras Ortop. 2016;51(6):725-9.

10. Pring ME. Pediatric radial neck fractures: when and how to fix. J Pediatr Orthop. 2012;32(Suppl 1):S14-21.

11. Ho-Fung VM, Zapala MA, Lee EY. Musculoskeletal traumatic injuries in children: characteristic imaging findings and mimickers. Radiol Clin N Am. 2017;55(4):785-802.

12. Eckert $K$, Janssen N, Ackermann $O$, Schweiger B, Radeloff E, Liedgens P. Ultrasound diagnosis of supracondylar fractures in children. European journal of trauma and emergency surgery : official publication of the European Trauma Society. 2014:40(2):159-68.

13. Rowlands R, Rippey J, Tie S, Flynn J. Bedside ultrasound vs X-ray for the diagnosis of forearm fractures in children. The Journal of emergency medicine. 2017:52(2):208-15.

14. Kodama N, Takemura Y, Ueba H, Imai S, Matsusue Y. Ultrasound-assisted closed reduction of distal radius fractures. The Journal of hand surgery. 2014;39(7):1287-94.

15. Soldado F, Knorr J, Haddad S, Diaz-Gallardo P, Palau-Gonzalez J, Mascarenhas W, Karmali S, de Gauzy JS. Ultrasound-guided percutaneous medial pinning of pediatric supracondylar humeral fractures to avoid ulnar nerve injury. The archives of bone and joint surgery. 2015;3(3):169-72.

16. Metaizeau JP. Reduction and osteosynthesis of radial neck fractures in children by centromedullary pinning. Injury. 2005;36(Suppl 1):A75-7.

17. Connolly B, Racadio J, Towbin R. Practice of ALARA in the pediatric interventional suite. Pediatr Radiol. 2006;36(Suppl 2):163-7.

18. Ali AA, Solomon DM, Hoffman RJ. Femur fracture diagnosis and management aided by point-of-care ultrasonography. Pediatr Emerg Care. 2016:32(3):192-4.

19. Hubner U, Schlicht W, Outzen S, Barthel M, Halsband H. Ultrasound in the diagnosis of fractures in children. The Journal of bone and joint surgery British volume. 2000;82(8):1170-3.
20. Maempel JF, Stone OD, Murray AW. Quantification of radiation exposure in the operating theatre during management of common fractures of the upper extremity in children. Ann R Coll Surg Engl. 2016;98(7):483-7.

21. Patel NG, Mohamed AM, Cooper G, McFadyen I. lonising radiation exposure in paediatric trauma. Ann R Coll Surg Engl. 2014;96(3):190-3.

\section{Submit your next manuscript to BioMed Central and we will help you at every step:}

- We accept pre-submission inquiries

- Our selector tool helps you to find the most relevant journal

- We provide round the clock customer support

- Convenient online submission

- Thorough peer review

- Inclusion in PubMed and all major indexing services

- Maximum visibility for your research

Submit your manuscript at www.biomedcentral.com/submit
Ciomed Central 